\title{
High Diagnostic Accuracy of Nitrite Test Paired with Urine Sediment can Reduce Unnecessary Antibiotic Therapy
}

\author{
Sven A. Ferry ${ }^{1, *}$, Stig E. Holm ${ }^{2}$, B. Magnus Ferry ${ }^{3}$ and Tor J. Monsen ${ }^{1}$ \\ ${ }^{I}$ Department of Clinical Microbiology, Bacteriology, Umea University, Umea, Sweden \\ ${ }^{2}$ Department of Medical Microbiology and Immunology, University of Gothenburg, Gothenburg, Sweden \\ ${ }^{3}$ Department of Education, Umea University, Umea, Sweden
}

\begin{abstract}
Background: Urinary tract infections (UTIs) are common bacterial infections dominated by lower UTI in women (LUTIW). Symptoms only are insufficient for diagnosis and accordingly, near patient diagnostic tests confidently confirming significant bacteriuria are desirable. The nitrite test (NIT) has low sensitivity, while bacterial and leukocyte counts disjunctively paired in urine sediment microscopy (SED) have high sensitivity. Similar symptomatic cure rates are found post antibiotic $v s$. placebo therapy in patients with negative cultures. Consequently, prescription on symptoms only implies unnecessary antibiotic therapy.
\end{abstract}

Aims: to evaluate the diagnostic outcomes of NIT, SED and NIT disjunctively paired with SED (NIT+SED) vs. urine culture, with special focus on bladder incubation time (BIT), and to assess if NIT+SED can reduce unnecessary antibiotic therapy.

Methods: A diagnostic, primary care, multicentre study including 1070 women with symptoms suggestive of lower UTI.

Results: Significant bacteriuria was found in $77 \%$. The BIT highly influenced the diagnostic outcomes and the optimal duration was $\geq 4$ h with sensitivity of 66,90 and $95 \%$ for NIT, SED and NIT+SED, respectively. SED performed only in NIT negative specimens could reduce unnecessary antibiotics by $10 \% v s$. prescription on symptoms only. The number needed to test with SED to reduce one unnecessary antibiotic course was five patients at BIT $\geq 4 \mathrm{~h}$ and six patients at $\leq 3 \mathrm{~h}$ or overall.

Conclusion: The BIT highly influences the diagnostic outcomes with the highest accuracy of NIT+SED. Diagnosis of LUTIW with NIT+SED can reduce unnecessary antibiotic therapy and subsequently decrease antimicrobial resistance.

Trial registration: The Swedish Medical Product Agency 199503 01:151:01783/94.

Keywords: Antibiotic resistance, bacteria, bladder incubation time, diagnosis, dipstick test, leukocytes, primary care, urinary tract infection.

\section{INTRODUCTION}

Urinary tract infections (UTIs) are common bacterial infections [1], estimated to 150 million episodes annually worldwide [2], dominated by uncomplicated, communityacquired, lower UTI in women (LUTIW) and often handled in primary care (PC) [3-5].

Patients with LUTIW often want rapid relief of intensive symptoms [6]. However, studies of UTI seldom focus on symptoms, as reported by only 9/464 studies in a metaanalysis [7]. Women with at least one symptom had $50 \%$ probability of UTI, while presence of two or more symptoms obtained $65 \%$ sensitivity and $69 \%$ specificity in a multicenter study [8]. A meta-analysis of symptomatic women

*Address correspondence to this author at the Department of Clinical Microbiology, University Hospital of Umea, SE-90185 Umea, Sweden; Tel: +46705782019; Fax: + 4690131802;

E-mail: sven.a.ferry@climi.umu.se concluded that clinical findings do not aid in the diagnosis [9], while a review found that individual symptoms only modestly increase the pretest probability of UTI [10]. Moreover, in a multicenter, placebo-controlled, therapy study, the LUTIW project, we found similar mean symptoms scores in women with negative culture as in those with significant bacteriuria (SBU) [6, 11]. Accordingly, symptoms only are insufficient for the diagnosis of UTI.

The nitrite test (NIT) is the most commonly used near patient diagnostic test with varying diagnostic outcomes [12$14]$, as $20-85 \%$ sensitivity in one meta-analysis [15] vs. 38 $62 \%$ in another [16], which also reported $73-100 \%$ specificity depending on different criteria for SBU.

UTIs frequently cause inflammation with increasing leukocyturia, often examined by urine microscopy, which however has no uniform methods or interpretive standards accepted and highly variable outcomes [12, 17]. Accordingly, a review of microscopy for bacteria with four 
different methods reported $61-96 \%$ sensitivity and $65-96 \%$ specificity [18], and a multicenter study of SED found $47 \%$ sensitivity and $81 \%$ specificity for bacteria $v s .87$ and $29 \%$ for leucocytes [19]. Though, high-power microscopy of leucocytes in stained SED obtained high inter-observer agreement [20]. A PC study analyzing bacteria disjunctively paired with leucocytes in SED (either or both positive defined as UTI) found $97 \%$ sensitivity and $39 \%$ specificity [21].

Previously, we reported similar symptomatic cure rates post pivmecillinam vs. placebo therapy in women with negative urine culture, but significantly higher post pivmecillinam in those with $\mathrm{SBU}[6,11]$. Hence, we concluded that SBU should be confirmed confidently before antibiotics are prescribed. In contrast, current management guidelines in the US [22], Norway [23], Scotland [24] and Sweden [25] recommend antibiotic prescription based on symptoms only. Moreover, empirical treatment is considered most cost-effective, but implies unnecessary antibiotic prescriptions [26] and subsequently increasing antimicrobial resistance [27]. Thus, bacterial antibiotic resistance is an increasing global problem related to the consumption of antimicrobials [28-31] and differing between antibiotics [32]. Also, the simultaneous decline in research of new antimicrobials is now threatening us back to the preantibiotic era [33]. However, decreased antibiotic resistance was found following reduction in antimicrobial prescribing by general practices [34]. Accordingly, it is important to reduce unnecessary antibiotic therapy.

As the general quality of reporting studies of diagnostic accuracy is not optimal [35], the STARD (Standards for Reporting of Diagnostic Accuracy) statement was developed to improve this quality [36]. In the LUTIW project NIT, SED and disjunctive pairing of NIT and SED (NIT+SED) were examined $v s$. urine culture [11]. This diagnostic process is further analyzed as follows:

The aims of the present study were to evaluate the diagnostic outcomes of NIT, SED and NIT+SED vs. urine culture as reference standard, with special focus on the influence of BIT and applying the STARD statement, and to assess if NIT+SED can reduce unnecessary antibiotic therapy in women with symptoms suggestive of lower UTI.

\section{MATERIALS AND METHODS}

\section{Inclusion}

Women aged 18 years and above with symptoms suggestive of lower UTI were considered for enrolment in the study, which was performed during ordinary office hours at 18 PC centers in northern Sweden between April 1995 and February 1998 [6, 11].The symptoms urgency, dysuria, suprapubic pain or loin pain were registered and graded as none, light, moderate or severe (score 0-3). A total symptoms score of $\geq 2$ was required for inclusion. Oral and written information were given and patients accepting participation gave written consent.

\section{Exclusion}

Patients were excluded as earlier reported [6, 11], including pregnancy, antibiotic therapy for UTI within the last month, genital infection, suspected pyelonephritis (temperature of $\geq 38.5^{\circ} \mathrm{C}$, CRP $\geq 25 \mathrm{mg} / \mathrm{L}$ or kidney tenderness by palpation), complicating factors as diabetes or abnormality of the urinary tract, urine incontinence requiring catheter or pads, or previous participation in the study.

\section{Study Design and Approvals}

The present study evaluated data from a prospective, consecutive, randomized, double-blind, placebo-controlled, PC, multicentre, therapy study $[6,11]$. Age (years), symptoms duration (days), symptoms scores (mean values) and BIT (hours, h) were registered at inclusion. The diagnostic outcomes of NIT, SED and NIT+SED were calculated in relation to urine culture as the reference standard. The STARD statement for reporting diagnostic studies was applied [35, 36]. The study was conducted in accordance with the Swedish Medical Product Agency guidelines and was approved by the Agency 1995-03$01: 151: 01783 / 94$ as well as by the Ethics Committee of Umea University 1995-03-07 (dnr 93-178, §195/9310, date 930924).

\section{Bladder Incubation Time and Urine Sampling}

The longest duration of BIT, or $\geq 4 \mathrm{~h}$ if possible, was recommended and most easily achieved in first morning urine samples. Thus, morning visits with such specimens were offered at the PC centers to patients accepting this management. Instructions were given including how to collect an MSU after separating the labia without prewashing the perineum. Urine specimens collected outside the PC centers were instructed to be refrigerated in a clean glass container before transported in a plastic bag containing ice cubes for delivery at the centers. The specimens were separated in two parts, and in the first part NIT and SED were performed immediately.

\section{Near patient Diagnostic Tests: NIT and SED}

Bacteria can reduce nitrate in the urine to nitrite, as indicated by a pink to red color change of the NIT dipstick. According to the manufacturer (Nitur-test ${ }^{\mathbb{R}}$, BoehringerMannheim, Mannheim, Germany), the NIT is calibrated for $\geq 10^{5} \mathrm{CFU} / \mathrm{mL}$, and the uropathogens need to act in the urine for $\geq 4 \mathrm{~h}$ to achieve the highest diagnostic accuracy. Within one minute after the stick was dipped in the urine, any color change was recorded, and at least light pink was defined as positive NIT.

The SED was performed as previously reported [21]. In summary, a $10-\mathrm{mL}$ tube with conical bottom was filled with urine, centrifuged for five minutes at 3750 rounds/minute $(1250 \mathrm{G})$, followed by careful decanting of the supernatant. One drop of Sternheimer-Malbin wet stain (Sedi-Stain ${ }^{\circledR}$, Becton, Dickinson and Company, Stockholm, Sweden) was added to and mixed with the sediment [37]. Then, a plastic capillary tube (inner diameter $2.5 \mathrm{~mm}$ ) was dipped in the suspension, and $3 \mu \mathrm{L}$ (range 2-5) was applied to a glass slide before a $18 \times 18 \mathrm{~mm}$ cover slip was placed on top [21]. Samples were examined with a light microscope (Zeiss standard model, Carl Zeiss AB, Stockholm, Sweden) having a 40/0.65 achromatic objective and a x 10 wide angle ocular for phase-contrast microscopy yielding a view field with a 
diameter of $450 \mu \mathrm{m}$ and a depth of focus of $1.3 \mu \mathrm{m}$ per high power field ( HPF, magnification x 400). At least five view fields were examined, and the average number of leukocytes and bacteria/HPF were recorded. Leukocytes were counted up to $15 / \mathrm{HPF}$ and then approximated as 20,25 , or $\geq 30 / \mathrm{HPF}$. The bacteria were difficult to count exactly due to their small size and often movements, but were classified as negative (no or a few bacteria), low (10-99), moderate (100-300) or high (innumerable) counts of bacteria/ HPF. The disjunctive pairing of at least a moderate bacterial count and $\geq 5$ leukocytes/HPF was defined as positive SED.

This SED technique was illustrated in the county management guidelines for UIT in PC [38], which was introduced for laboratory staffs and physicians more than ten years before the start of the LUTIW project. At introduction of the project, all physicians and staff members involved were instructed of the centrifugation and microscopy technique according to a protocol, including a collection of colored sediment images. In addition, magnified sediment samples were shown. At each centre the centrifuge and microscope were calibrated, followed by a supervised practice session. The SED analyses were performed by experienced laboratory technicians at three centers, but by physicians or assistant nurses at the other 15 centers.

\section{Bacteriological Methods}

The second part of the urine specimen was transported in a 10 -mLsterile glass tube chilled at $<6^{\circ} \mathrm{C}$ within $24 \mathrm{~h}$ to the Laboratory of Clinical Bacteriology, University Hospital of Umea for urine culture [11]. In summary, $10 \mu \mathrm{L}$ was inoculated on cystine-lactose-electrolyte deficient agar (CLED, Acumedia Manufacturers, Inc. Baltimore, Maryland, USA), and incubated at $35^{\circ} \mathrm{C}$ for $18-20 \mathrm{~h}$. The uropathogens were quantified and reported in $\mathrm{CFU} / \mathrm{mL}$, and identified as previously described. SBU was defined according to guidelines stating cut-off levels of $\geq 10^{3}$ for primary (E. coli and $S$. saprophyticus), $\geq 10^{4}$ for secondary and $\geq 10^{5} \mathrm{CFU} / \mathrm{mL}$ for doubtful uropathogens [12]. In cultures with mixed flora

\section{Urine culture}

Bladder incubation time

Nitrite test

\section{Urine sediment}

and one predominant species (at least 10-fold higher $\mathrm{CFU} / \mathrm{mL}$ than that of any other species), the major species were defined as an uropathogen [11]. Non-significant bacteriuria was defined as negative culture. Samples with mixed flora without one predominant species were considered contaminated and defined as negative culture.

\section{Statistical Analyses}

The statistical outcomes sensitivity, specificity, predictive values and false results were calculated using the predictive value theory [39]. Efficacy was defined as the percentage correct diagnosis, i.e. 100 minus false (positive and negative) results. Comparison of proportions was done using chi-square test or Fisher's exact test. Pvalues $<0.05$ were considered as statistically significant. The software used for statistical calculation was IBM SPSS 21.0 (IBM Corp., Armonk, New York, USA) and Stat View version 5.0.1 (SAS Institute Inc., Cary, North Carolina, USA).

\section{RESULTS}

In total, 1143 women with urine culture performed were eligible for enrolment in the present study (Fig. 1.) Of those, 73 patients $(6 \%)$ were excluded due to missing BIT in 16 patients, NIT in three more and SED in another 54. The remaining 1070 patients included had a mean age of 43 years $( \pm 18)$, median symptom duration of four days and mean symptoms score of 5.3 (range 2-12). The symptoms reported were $96 \%$ urgency, $88 \%$ dysuria, $60 \%$ suprapubic pain and $40 \%$ loin pain. The excluded patients had similar characteristics, symptoms and culture results as those included (data not shown).

SBU was found in $77 \%$ of the included patients (827/1070), of which E. coli dominated in 81\% (Table 1).

Mixed bacterial flora was found in $13 \%$, of which $7 \%$ with one predominant species were reported as a uropathogen and $6 \%$ were reported as culture negative. The

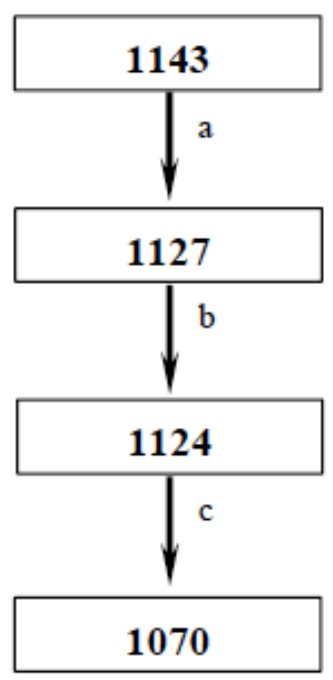

Fig. (1). Flow chart of the diagnostic parameters reported in women with symptoms suggestive of lower UTI resulting in patients included in the diagnostic study (n). ${ }^{\mathrm{a}}$ Bladder incubation time missed in 16 patients; ${ }^{\mathrm{b}}$ Nitrite test missed in three more patients; ${ }^{\mathrm{c}}$ Urine sediment missed in 54 further patients. 
Table 1. Distribution of bacterial species and bacterial counts in urine cultures in relation to bladder incubation time in women with symptoms suggestive of lower UTI.

\begin{tabular}{|c|c|c|c|c|c|}
\hline \multirow{3}{*}{ Urine culture and bacterial species } & \multirow{3}{*}{$\mathbf{B C}^{\mathbf{a}}$} & \multicolumn{4}{|c|}{ Bladder incubation time } \\
\hline & & \multirow{2}{*}{$\frac{\leq 3 \mathrm{~h}}{\mathrm{n}}$} & \multirow{2}{*}{$\frac{\geq 4 h}{n}$} & \multicolumn{2}{|c|}{ Total } \\
\hline & & & & $\mathbf{n}$ & $\%$ \\
\hline \multirow{4}{*}{ E.coli ${ }^{* * *}$} & $10^{3}$ & 27 & 10 & 37 & 6 \\
\hline & $10^{4}$ & 55 & 12 & 67 & 10 \\
\hline & $\geq 10^{5}$ & 202 & 361 & 563 & 84 \\
\hline & Total & 284 & 383 & 667 & 62 \\
\hline \multirow{3}{*}{ Other G-neg ${ }^{c} \operatorname{spp}^{\mathrm{b}}$} & $10^{4}$ & 2 & 0 & 2 & 4 \\
\hline & $\geq 10^{5}$ & 12 & 42 & 54 & 96 \\
\hline & Total & 14 & 42 & 56 & 5 \\
\hline \multirow{3}{*}{ S. saprophyticus } & $10^{4}$ & 3 & 5 & 8 & 12 \\
\hline & $\geq 10^{5}$ & 31 & 30 & 61 & 88 \\
\hline & Total & 34 & 35 & 69 & 6 \\
\hline \multirow{3}{*}{ Other G-pos ${ }^{\mathrm{d}} \mathrm{spp}^{\mathrm{b}}$} & $10^{4}$ & 5 & 3 & 8 & 23 \\
\hline & $\geq 10^{5}$ & 14 & 13 & 27 & 77 \\
\hline & Total & 19 & 16 & 35 & 3 \\
\hline Negative culture $^{e}$ & $0^{\mathrm{e}}$ & $117^{\mathrm{f}}$ & $126^{\mathrm{g}}$ & 243 & 23 \\
\hline \multirow{4}{*}{ All cultures**** } & $0^{\mathrm{e}}$ & 117 & 126 & 243 & 23 \\
\hline & $10^{3}$ & 27 & 10 & 37 & 3 \\
\hline & $10^{4}$ & 65 & 20 & 85 & 8 \\
\hline & $\geq 10^{5}$ & 259 & 446 & 705 & 66 \\
\hline \multirow{2}{*}{ Total } & $\mathrm{n}$ & 468 & 602 & 1070 & \\
\hline & $\%$ & 44 & 56 & 100 & 100 \\
\hline
\end{tabular}

${ }^{\mathrm{a}}$ Bacterial counts in colony forming units $/ \mathrm{mL} ;{ }^{\mathrm{b}}$ Species; ${ }^{\mathrm{c}}$ Other Gram-negative spp: 28 Klebsiella spp, 12 Citrobacter, 12 Enterobacter, 6 Proteus spp, 2 Pseudomonas spp; ${ }^{\mathrm{d}}$ Other Gram-positive spp: 21 Enterococcus spp, 7 S. auerus, 5 Coagulase-negative staphylococci other than S.saprophyticus, 5 Group B streptococci; ${ }^{\mathrm{e}}$ Negative culture, see Methods; ${ }^{\mathrm{f}} 25 \%$ of all negative cultures; ${ }^{\mathrm{g}} 21 \%$ of all negative cultures; ${ }^{* * * *}$ p $<0.001$ : Statistical differences in bacterial counts between bladder incubation time $\leq 3 \mathrm{~h} v s . \geq 4 \mathrm{~h}$.

mean BIT was $4.2 \mathrm{~h}( \pm 2.5)$ and $56 \%$ of the patients achieved a BIT of $\geq 4 \mathrm{~h}$ (Table 2 ). The bacterial counts in SED and urine cultures were highly influenced by the duration of BIT $(\mathrm{p}<0.001)$, especially for $E$. coli (Table 1$)$. This was illustrated by the high bacterial counts of $\geq 10^{5} \mathrm{CFU} / \mathrm{mL}$ in $94 \%$ at BIT $\geq 4 \mathrm{~h} v s$. $71 \%$ at BIT $\leq 3 \mathrm{~h}$. Since no further increase of bacterial counts was observed for BITs $>4 \mathrm{~h}$, the BIT $\geq 4 \mathrm{~h}$ was found to be the optimal duration and thus used as cut-off level in the further analyses. Negative culture was found in 243 patients $(23 \%)$ without significant influence by the BIT $(25 \%$ at $\operatorname{BIT} \leq 3 \mathrm{~h}$ vs. $21 \%$ at $\geq 4 \mathrm{~h}, \mathrm{p}=0.123)$.

The diagnostic outcomes of NIT were highly influenced by the BIT. The sensitivity and efficacy increased from 30 and $47 \%$ for BIT $\leq 3 h$ to 66 and $72 \%$ for $\geq 4 h(p<0.001$, Table 3). However, the BIT had lower impact on the specificity and positive predictive value, which on average were found in 95 and $97 \%$. E. coli had the highest sensitivity increasing from 60 to 63 and $67 \%$ for bacterial counts of $10^{3}$, $10^{4}$ and $\geq 10^{5} \mathrm{CFU} / \mathrm{mL}$ compared to 49,52 and $57 \%$ in all culture positive specimens, respectively.

The BIT had lower impact on the outcomes of SED, which were similar and consistent at all centers during the study period (data not shown). However, the bacterial counts highly increased by the duration of BIT $(p<0.001)$ but the leukocyte counts were similar. Accordingly, the sensitivity of SED was $88 \%$ fort BIT $\leq 3 \mathrm{~h}$ and $92 \%$ for BIT $\geq 4 \mathrm{~h}$ $(p=0.079$, Table 3). The influence of BIT on the other diagnostic outcomes was low, with averages of $46 \%$ specificity and $85 \%$ positive predictive value. Thus, the diagnostic efficacy was overall higher for SED compared to NIT (80 vs. 61\%, p<0.001).

Since the BIT had also high influence on the diagnostic outcomes of NIT+SED, the sensitivity increased from $89 \%$ for BIT $\leq 3 \mathrm{~h}$ to $95 \%$ for BIT $\geq 4 \mathrm{~h}(\mathrm{p}<0.01$, Table 3$)$. Also, the 
Table 2. Outcomes of nitrite test, urine sediment and urine culture in relation to bladder incubation time in women with symptoms suggestive of lower UTI (n).

\begin{tabular}{|c|c|c|c|c|c|}
\hline \multirow{2}{*}{ BIT $^{\mathbf{a}}$} & \multirow{2}{*}{ Nitrite test ${ }^{\mathrm{b}}$} & \multirow{2}{*}{ Urine sediment $^{\mathrm{c}}$} & \multicolumn{3}{|c|}{ Urine culture $^{\mathrm{d}}$} \\
\hline & & & Negative & Positive & Total \\
\hline \multirow{5}{*}{$\leq 3 \mathrm{~h}$} & \multirow{2}{*}{ Negative $^{e}$} & Negative & 55 & 38 & 93 \\
\hline & & Positive & 59 & 207 & 266 \\
\hline & \multirow{2}{*}{ Positive } & Negative & 2 & 5 & 7 \\
\hline & & Positive & 1 & 101 & 102 \\
\hline & All & & 117 & 351 & 468 \\
\hline \multirow{5}{*}{$\geq 4 \mathrm{~h}$} & \multirow{2}{*}{ Negative $^{f}$} & Negative & 52 & 25 & 77 \\
\hline & & Positive & 66 & 136 & 202 \\
\hline & \multirow{2}{*}{ Positive } & Negative & 2 & 15 & 17 \\
\hline & & Positive & 6 & 300 & 306 \\
\hline & All & & 126 & 476 & 602 \\
\hline \multirow{5}{*}{ Total } & \multirow{2}{*}{ Negative $^{g}$} & Negative & 107 & 63 & 170 \\
\hline & & Positive & 125 & 343 & 468 \\
\hline & \multirow{2}{*}{ Positive } & Negative & 4 & 20 & 24 \\
\hline & & Positive & 7 & 401 & 408 \\
\hline & All & & 243 & 827 & 1070 \\
\hline
\end{tabular}

${ }^{a}$ BIT, bladder incubation time (h); ${ }^{b}$ Positive Nitrite test, see Methods $;{ }^{c}$ Positive Urine sediment, see Methods;

${ }^{\mathrm{d}}$ Positive Urine culture, see Methods; ${ }^{\mathrm{e}} 77 \%$ of all patients at BIT $\leq 3 \mathrm{~h} ;{ }^{\mathrm{f}} 46 \%$ of all patients at BIT $\geq 4 \mathrm{~h} ;{ }^{\mathrm{g}} 60 \%$ of all patients overall irrespective of BIT.

Table 3. Statistical outcomes of nitrite test, urine sediment and their disjunctive pairing in relation to bladder incubation time in women with symptoms suggestive of lower UTI (\%).

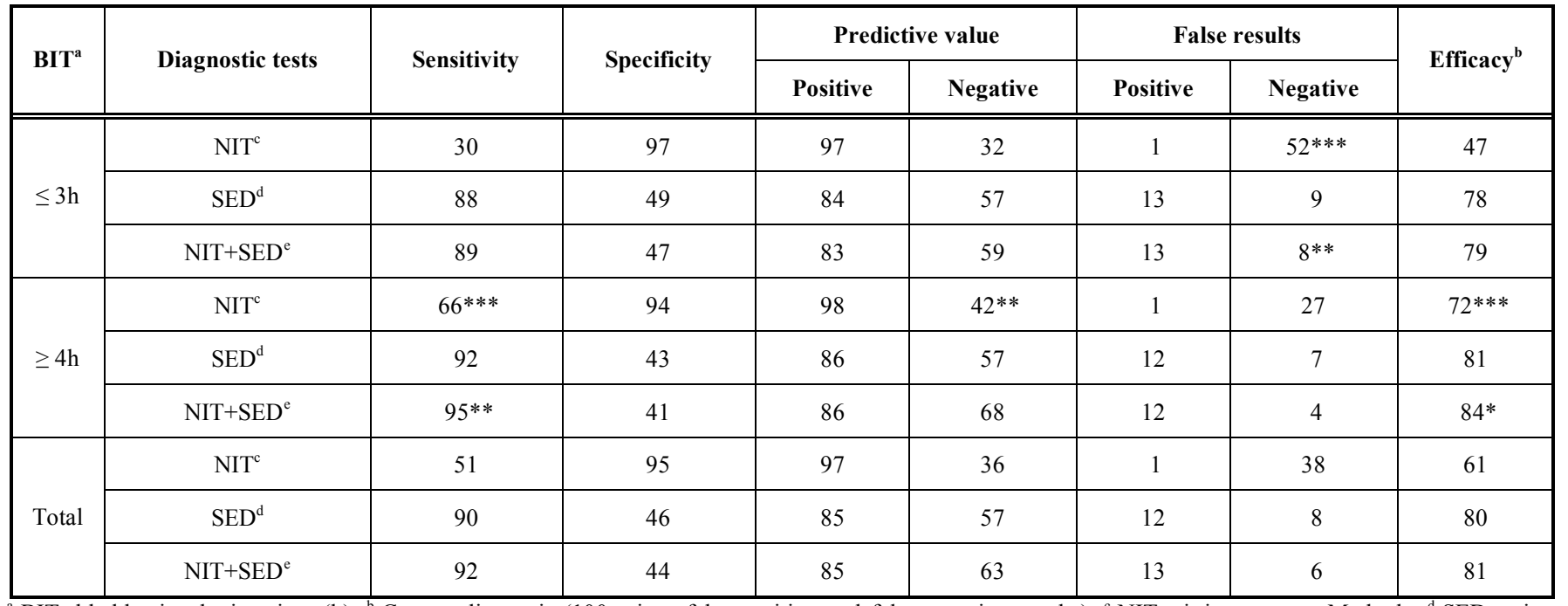

${ }^{a}$ BIT, bladder incubation time (h); ${ }^{b}$ Correct diagnosis (100 minus false positive and false negative results); ${ }^{\mathrm{c}}$ NIT, nitrite test, see Methods; ${ }^{\mathrm{d}}$ SED, urine sediment, see Methods; ${ }^{\mathrm{e}}$ NIT+SED, disjunctive pairing of NIT and SED (either and/or both positive defined as UTI); ${ }^{*} \mathrm{p}<0.05 ;{ }^{* *} \mathrm{p}<0.01 ; * * * \mathrm{p}<0.001$ : Statistical differences in proportions between BIT $\leq 3 \mathrm{~h} v s . \geq 4 \mathrm{~h}$.

efficacy increased from 79 to $84 \%$, respectively $(\mathrm{p}<0.05)$. In contrast, the false negative results decreased from $8 \%$ for $\mathrm{BIT} \leq 3 \mathrm{~h}$ to $4 \%$ for $\geq 4 \mathrm{~h}(\mathrm{p}<0.01)$. However, the BIT had low impact on specificity and positive predictive value, which on average were found in 44 and $85 \%$. Accordingly, NIT+SED had the highest diagnostic accuracy with the highest efficacy overall for BIT $\geq 4 \mathrm{~h}(84 \%)$, which was significantly higher compared to NIT $(72 \%, \mathrm{p}<0.001)$ and tended to be higher than for SED $(81 \%, \mathrm{p}=0.585)$. 


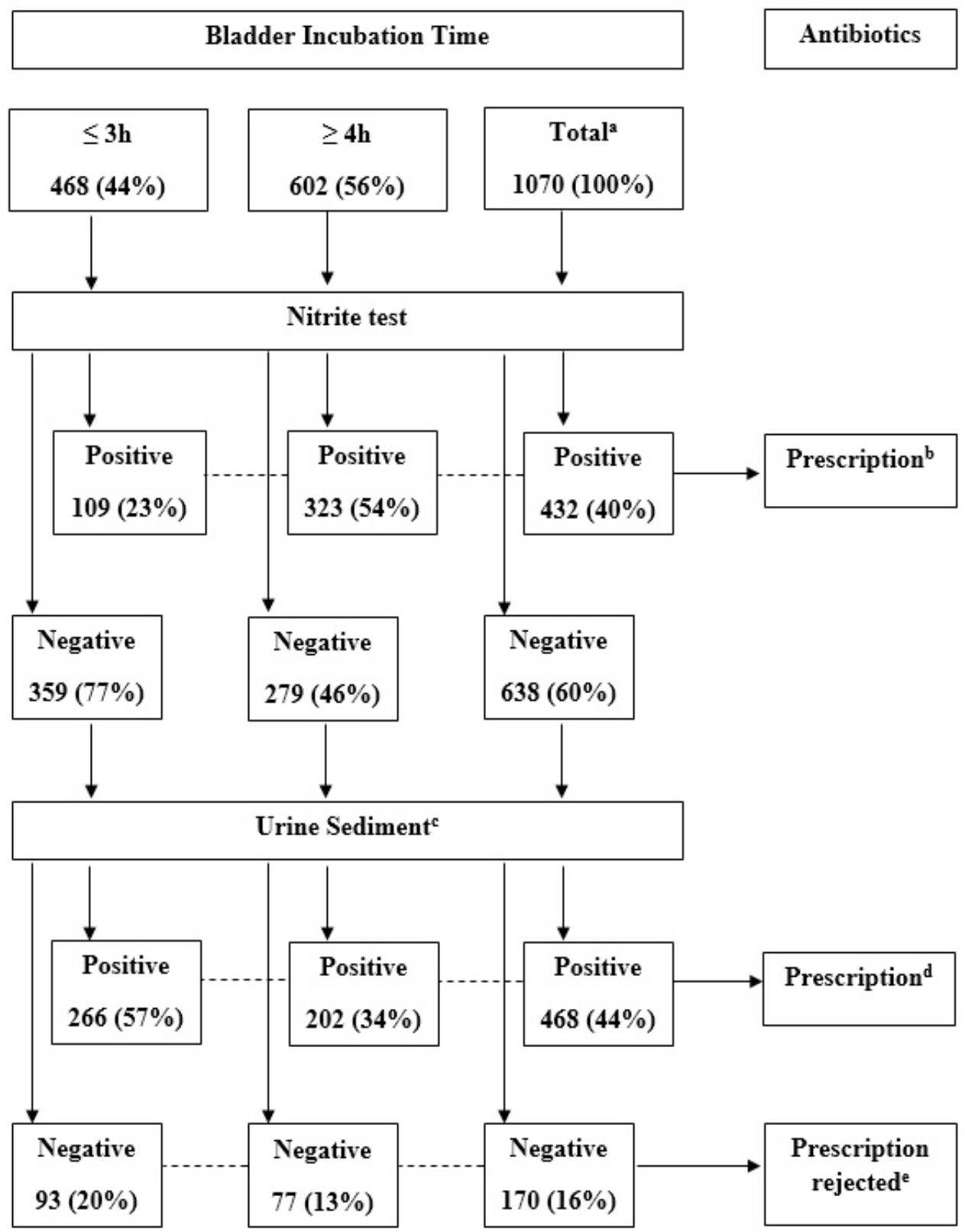

Fig. (2). Bladder incubation time, nitrite test and urine sediment $v$ s. urine culture in diagnosing women with symptoms suggestive of lower UTI resulting in prescription of antibiotics or prescription rejected.

${ }^{\mathrm{a}}$ Overall, irrespective of bladder incubation time (BIT); ${ }^{\mathrm{b}}$ Incorrect prescription in three patients at BIT $\leq 3 \mathrm{~h}(1 \%)$, eight at BIT $\geq 4 \mathrm{~h}(1 \%)$ and 11 overall (1\%); ${ }^{\mathrm{c}}$ Urine sediment, see Methods; ${ }^{\mathrm{d}}$ Incorrect prescription in 59 patients at BIT $\leq 3 \mathrm{~h}(13 \%), 66$ at BIT $\geq 4 \mathrm{~h}(11 \%)$ and 125 in total $(12 \%)$; ${ }^{\mathrm{e}}$ Prescription incorrectly rejected in 38 patients at BIT $\leq 3 \mathrm{~h}(8 \%), 25$ patients at BIT $\geq 4 \mathrm{~h}(4 \%)$ and 63 patients overall $(6 \%)$.

Further, we evaluated the diagnostic outcomes in a management model when SED was performed only in NIT negative specimens (Fig. 2), which occurred in $77 \%$ at BIT $\leq 3 \mathrm{~h}$, in $46 \%$ at BIT $\geq 4 \mathrm{~h}$ and on average in $60 \%$ (Table 2). With this management model patients would have been prescribed antibiotics overall to $80 \%(23+57 \%$, Fig. 2$)$ and unnecessarily to $13 \%$ (false positive, Table 3 ) at BIT $\leq 3 \mathrm{~h}$ $v s .88$ and $12 \%$ at BIT $\geq 4$ h (Fig 2. and Table 3 ), and overall to 84 and $13 \%$, respectively. Accordingly, compared to antimicrobial treatment based on symptoms only, application of NIT+SED could reduce unnecessary antibiotic prescriptions by $12 \%(25-13 \%$, Tables 1 and 3$)$ at $\mathrm{BIT} \leq 3 \mathrm{~h}$, by $9 \%(21-12 \%)$ at $\mathrm{BIT} \geq 4 \mathrm{~h}$ and on average by $10 \%$ (23-
$13 \%$ ). Thus, the number needed to test with SED, in order to reduce one unnecessary antibiotic course, were five patients at $\mathrm{BIT} \geq 4 \mathrm{~h}(1 / 0.09 \times 0.46=5.11)$ and six patients at $\mathrm{BIT} \leq 3 \mathrm{~h}$ $(1 / 0.12 \times 0.77=6.42)$ as well as six patients overall $(1 / 0.10 \times$ $0.60=6.00)$.

\section{DISCUSSION}

To our knowledge, the present study is the first comprehensive multicenter study of uncomplicated LUTIW in PC evaluating the diagnostic outcomes of NIT, SED and NIT + SED with focus on the influence of BIT. Since information about the importance of long duration of BIT 
was emphasized, just more than half of the patients achieved a BIT of $\geq 4 \mathrm{~h}$, which highly increased the bacterial counts in urine culture as in SED. Accordingly, SBU was obtained in $77 \%$ of the patients, which frequency is higher as compared to most studies in literature [15, 16, 40-43]. As the BIT also had high impact on NIT, the sensitivity of NIT was higher than in literature. Since NIT obtained very high specificity and positive predictive value overall, a positive NIT confidently confirmed diagnosis of UTI, which is in accordance with literature. SED had higher diagnostic accuracy than NIT but similar to that reported in a previous PC study [21]. The BIT also highly influenced outcomes of NIT+SED, which had the highest diagnostic efficacy for BIT $\geq 4$ h.

We evaluated the management model with SED performed only in NIT negative specimens, which overall concerned $60 \%$ of the patients. This management resulted in antibiotic prescription overall to $84 \%$ and unnecessarily to $13 \%$. Moreover, this model was effective for reducing unnecessary antimicrobial therapy, as the number needed to test with SED, in order to prevent one unnecessary course of antibiotics, were only five patients at BIT $\geq 4 \mathrm{~h}$ and six patients at BIT $\leq 3 \mathrm{~h}$ as well as six patients overall.

In most guidelines for the evaluation of new antimicrobial treatment of UTI, neither BIT nor sampling technique is mentioned [22-24, 45], which also concern most published diagnostic studies of UTI [15, 16, 40, 41]. The Swedish diagnostic guidelines for LUTIW applied in the present study [12] have cut-off levels for SBU varying from $\geq 10^{3}$ to $\geq 10^{5} \mathrm{CFU} / \mathrm{mL}$ for different uropathogens. These guidelines were revised in 2000 with preserved levels for SBU [42] and then also approved in Europe [43]. The American diagnostic guidelines for UTI are differing from the other guidelines, with criterion for SBU of $\geq 10^{3} \mathrm{CFU} / \mathrm{mL}$ for all uropathogens in LUTIW [44]. However, if the American guidelines had been implemented in the present study, this would only have had minor influence on the diagnostic outcomes. Accordingly, we consider that the applied criteria for SBU are valid for the diagnosis of LUTIW.

The longest possible BIT is recommended in diagnostic guidelines for UTI $[12,42-45]$, and $\geq 4 \mathrm{~h}$ is recommended by the manufacturer for obtaining the highest diagnostic accuracy. We found that BIT highly influenced most diagnostic outcomes, but BIT $>4 \mathrm{~h}$ did not further improve the diagnostic accuracy. Thus, we conclude that the optimal duration of BIT is $\geq 4 \mathrm{~h}$.

In the present study MSU specimens were collected after separating the labia without prewashing the perineum. However, the clean-catch sampling technique with separating the labia and cleansing the perineum before collecting a MSU specimen has been recommended for decades [13]. Though, that procedure is difficult both to understand and perform adequately, and its clinical documentation is sparse [46]. Similar distribution of uropathogens and contamination rates were found in homevoided specimens without prewashing as in clean-catch specimens voided at PC centers [47]. Also, similar findings were obtained in MSU specimens collected at PC centers irrespective of clean-catch or not [48-51]. Consequently, the sampling technique for collecting MSU specimens applied in the present study is valid.

Both internal and external quality controls are recommended in order to achieve high validity and reliability of near patient diagnostic tests $[35,36]$. The local guidelines for the management of UTI in PC including the SED method were introduced for staffs and physicians in PC and repeatedly trained before and after the LUTIW project. This probably increased the quality of management of UTI at the centers in the present study. Hence, we recommend PC centers to participate in education and training of management guidelines for UTI.

Scottish guidelines discourage from use of urine microscopy due to requirements of maintenance of equipment and training of the staff [24]. However, 15 centers with SED performed by physicians or assistant nurses, had similar outcomes of SED as the three centers with experienced laboratory technicians, and the SED data were consistent during the study period supporting the reliability of the method. Furthermore, SED is fast to perform and the material costs are about the same as for urine dipsticks with multiple tests. Since SED is also valid and easy to learn, we recommend our proposed diagnostic model of SED for the application in clinical practice.

There are few published studies of UTI performing NIT and SED for diagnostics of UTI. A multicenter study of NIT and high-power microscopy of leukocytes in SED reported $62 \%$ sensitivity and $89 \%$ specificity for NIT as 84 and $35 \%$ for leukocytes [52]. Disjunctive pairing of NIT and leukocytes obtained the highest diagnostic accuracy with $93 \%$ sensitivity and $17 \%$ specificity. Thus, the sensitivity was similar, but the specificity was lower, compared to NIT+SED in the present study.

The urinary leukocytes are currently often examined in clinical practice by the leukocyte esterase test (LE). In one meta-analysis of symptomatic patients the sensitivity range was $40-100 \%$ [15] vs. $60-98 \%$ in a second meta-analysis [16], also reporting 32-68\% specificity. The true and false positive rates for the tests were interdependent and remarkably heterogeneous [15]. Outcomes of combined dipsticks with NIT and LE disjunctively paired (NIT+LE) had the highest diagnostic accuracy with $61-93 \%$ sensitivity and $63-78 \%$ specificity [16]. However, negative NIT+ LE did not rule out infection in a multicenter study of symptomatic women, as SBU was found in 50\% of these specimens [14]. Accordingly, combinations of these tests are unreliable for the diagnosis of UTI.

In two multicenter studies of symptomatic women, SBU was found in 63 and $66 \%[8,53]$. A diagnostic model based on nitrite and/or both leukocytes and erythrocytes defined as confirmed UTI, reported $77 \%$ sensitivity and $70 \%$ specificity in the first study vs. 75 and $60 \%$ in the second, respectively. Thus, the diagnostic accuracy for combination of those dipstick tests was overall lower vs. NIT+SED in the present study.

Two other multicenter studies of suspected LUTIW applied different criteria for SBU, which were reported in 53 and $63 \%[54,55]$. Patients with urgency or dysuria were offered antimicrobial treatment by telephone without 
urinalysis. Antibiotics were prescribed overall to $81 \%$ and unnecessarily to $40 \%$ of the patients in the first study $v s .89$ and $29 \%$ in the second, respectively. A management model based on the factors dysuria, nitrite and leukocytes on dipsticks, defined the presence of at least two factors as confirmed UTI diagnosis and recommended antimicrobial prescription. The presence of one of the factors was considered as unreliable and proposed to await outcome of urine culture for confident diagnosis. If that management was applied, antibiotic prescriptions would have decreased overall to $60 \%$ and unnecessarily to $28 \%$ in the first study $v s$. 68 and $17 \%$ in the second, respectively. Hence, lower diagnostic accuracy and higher frequency of unnecessary antibiotic prescriptions were obtained $v s$. management with NIT+SED in the present study.

In the present study, the sensitivity of NIT + SED was higher than for most studies of NIT+LE according to literature $[15,16,40,41]$, presumably due to the disjunctive pairing of bacteria and leucocytes in SED. NIT+SED had the highest diagnostic accuracy for BIT $\geq 4 \mathrm{~h}$, with a very high sensitivity and a low proportion of false negative results, resulting in few incorrectly rejected antibiotic prescriptions. Moreover, most patients had decreasing symptoms by placebo therapy [6] and only one of those 288 patients developed pyelonephritis [11]. Accordingly, we consider that these minor risks for complications achieved by NIT+SED are satisfactory and up to now, this is the most accurate model for near patient diagnostics of LUITW.

We found that our proposed management model with NIT+SED applied in patients with symptoms suggestive of LUTIW, can reduce unnecessary antibiotic prescriptions by an average of $10 \% v s$. prescription based on symptoms only, which subsequently can decrease antimicrobial resistance. If this management was implemented in clinical practice worldwide, this reduction could be estimated to 15 million episodes annually [2]. However, the abuse of unnecessary antimicrobials is probably much more extensive, as considerably lower proportions of SBU are found in clinical practice in patients with symptoms suggestive of lower UTI as compared to the present study. This is previously reported $[8,53-55]$ and also illustrated by a multicenter study with SBU found in only $21 \%$ of patients with suspected UTI [56]. Consequently, even larger reduction of unnecessary antimicrobial consumption and decreased antibiotic resistance can be expected than those indicated in the present study.

The strengths of the presents study are firstly, the comprehensiveness with high frequency of SBU and low proportion of contaminated cultures. Secondly, the optimal BIT of $\geq 4 \mathrm{~h}$ was obtained in many patients with high influence on the diagnostic process. Thirdly, the STARD statement for accurate reporting of diagnostic studies was applied, whereby methods and results were thoroughly described in both the present study and literature. We presume that this enable the readers to assess the potential for bias in the present study and to evaluate the generalisability of the results.

The limitations of the study are firstly, that the LUTIW project was performed more than ten years ago. However, the criteria for SBU and the distribution of uropathogens causing uncomplicated LUTIW have remained similar for decades and accordingly, the results of the present study are still valid. Secondly, the study was performed at ordinary office hours. Though, if patients also had been included at out of office hours, this probably would have resulted in shorter BITs and lower diagnostic accuracy. Thirdly, after planning of the study, dipsticks with multiple tests including LE for urinalysis were introduced in clinical practice, which however, have lower diagnostic accuracy $v s$. NIT+SED in the present study.

In order to obtain high diagnostic accuracy in patients with symptoms suggestive of UTI, pre analytical procedures have to be highlighted. These procedures concern BIT, sampling technique, storage, transport and preparation of the specimens for urinalysis, as well as careful and wellstandardized performance of the diagnostic methods [57], which were given high attention in the present study. The applied MSU sampling technique was easy for the patients to understand and perform. Many patients accepted morning visits and first morning specimens, which extent we unfortunately did not register. However, our experience supports that this is easy to implement, if patients are informed by the staffs and physicians about the importance of BIT $\geq 4 \mathrm{~h}$. To summarize, we consider that our proposed management model with NIT+SED is valid and suitable for patients, staffs and physicians to implement in clinical practice, and also for researchers to implement in the management guidelines for UTI.

As studies of urine microscopy are rather sparsely published, further diagnostic multicenter studies of patients with symptoms suggestive of lower UTI in PC from different countries evaluating SED are desirable, but also studies combining SED with multiple dipstick tests. Hopefully, such studies will verify the results from the present study and also further improve the management of UTI in clinical practice.

\section{CONCLUSION}

NIT+SED have the highest diagnostic accuracy of near patient diagnostic tests for LUTIW.

The BIT highly influences the diagnostic outcomes of LUTIW with $\geq 4 \mathrm{~h}$ as optimal duration.

Implementation of NIT+SED can reduce unnecessary antibiotic prescriptions in LUTIW and subsequently decrease antimicrobial resistance.

The number needed to test with SED in NIT negative specimens, in order to reduce one unnecessary course with antibiotics, is only five patients at BIT $\geq 4 \mathrm{~h}$ and six patients at BIT $\leq 3 \mathrm{~h}$ as well as six patients overall.

\section{CONFLICT OF INTEREST}

The authors have no conflicts of interest to declare.

\section{ACKNOWLEDGEMENTS}

The authors are grateful to the patients and staff at the 18 participating PC centers, and to Carina Karlsson and Catharina Lundgren at the Department of Clinical Bacteriology, University Hospital of Umea, for technical assistance, and to the data reviewer Ulf Diehl, who also monitored the study, 
together with Gunilla Ljunghagen, LEO Pharma, Malmo, Sweden. Associate professor Lars G. Burman, of the Swedish Institute for Infectious Disease Control, Stockholm, Sweden, is thanked for his valuable criticism of the manuscript.

The study was supported by LEO Pharma, Malmo, Sweden and by grants from the County Council of Vasterbotten and Umea University, Umea, Sweden.

\section{REFERENCES}

[1] Foxman B. Epidemiology of urinary tract infections: incidence, morbidity, and economic costs. Am J Med 2002; 113: 5-13.

[2] Kucheria R, Dasgupta P, Sacks SH, et al. Urinary tract infections: new insights into a common problem. Postgrad Med J 2005; 81: 83-6.

[3] Hooton TM. Pathogenesis of urinary tract infections: an update. J Antimicrob Chemother 2000; 46 (Suppl 1): 1-7.

[4] Hummers-Pradier E, Kochen MM. Urinary tract infections in adult general practice patients. Br J Gen Pract 2002; 52: 752-61.

[5] Kahlmeter G. Prevalence and antimicrobial susceptability of pathogens in uncomplicated cystitis in Europe. The ECO.SENS study. Int J Antimicrob Agents 2003; 22 (Suppl 2): 49-52.

[6] Ferry SA, Holm SE, Stenlund H, et al. The natural course of uncomplicated lower urinary tract infection in women illustrated by a randomized placebo controlled study. Scand J Infect Dis 2004; 6: 296-301.

[7] Bent S, Nallamouthu BK, Simel DL, et al. Does this woman have an acute uncomplicated urinary tract infection? JAMA 2002; 287: 2701-10.

[8] Little P, Turner S, Rumsby K, et al. Developing clinical rules to predict urinary tract infection in primary care settings: sensitivity and specificity of near patient tests (dipsticks) and clinical scores. Br J Gen Pract 2006; 56: 606-12.

[9] Medina-Bombardó D, Jover-Palmer A. Does clinical examination aid in the diagnosis of urinary tract infections in women? A systematic review and meta-analysis. BMC Fam Pract 2011 Oct 10; 12: 111.

[10] Giesen LGM, Cousins G, Dimitrov BD, et al. Predicting acute uncomplicated urinary tract infection in women: a systematic review of the diagnostic accuracy of symptoms and signs. BMC Fam Pract 2010 Oct 24; 11: 78 .

[11] Ferry SA, Holm SE, Stenlund H, et al. Clinical and bacteriological outcome of different doses and duration of pivmecillinam compared with placebo therapy of uncomplicated lower urinary tract infection in women: the LUTIW project. Scand J Prim Health Care 2007; 25: 49-57.

[12] Hallander H, ed. Referensmetodik for laboratoriediagnostik vid kliniskt bakteriologiska laboratorier. I. Infektionsdiagnostik. I 5. Urinvagsinfektioner/bakteriuri. Smittskyddsinstitutet 1993 (In Swedish). [Reference methodology for laboratory diagnostics at clinical bacteriological laboratories. I. Infectious diagnostics. I 5. Urinary tract infections/bacteriuria]. Solna, Sweden: The Swedish Institute for Infectious Disease Control; 1993.

[13] Kunin CM. Urinary tract infections: detection, prevention, and management. $5^{\text {th }}$ ed. Williams \& Wilkins: Baltimore, Maryland, USA, 1997.

[14] Nys S, van Merode T, Bartelds AIM, et al. Urinary tract infections in general practice patients: diagnostic tests versus bacteriological culture. J Antimicrob Chemother 2006; 57: 955-8.

[15] Hurlbut III TA, Littenberg B, and the Diagnostic Technology Assessment Consortium. The diagnostic accuracy of rapid dipstick tests to predict urinary tract infection. Am J Clin Pathol 1991; 96: 582-8.

[16] Devillé WLJM, Yzermans JC, van Duijn NP, et al. The urine dipstick test useful to rule out infections. A meta-analysis of the accuracy. BMC Urol 2004 Jun 2; 4: 4.

[17] Winkel P, Stalland BE, Jorgensen K. Urine microscopy, an illdefined method, examined by a multifactor technique. Clin Chem 1974; 20: 436-9.

[18] Jenkins RD, Fenn JO, Matsen JM. Review of urine microscopy for bacteriuria. JAMA 1986; 253: 3307-403.
[19] Winkens RAG, Leffers P, Trienekens TAM, et al. The validity of urine examination for urinary tract infections in daily practice. $\mathrm{J}$ Fam Pract 1995; 11: 290-3.

[20] Baerheim A, Albrektsen G, Eriksen AG, et al. Quantification of pyuria by two methods. correlation and interobserver agreement. Scand J Prim Health Care 1989; 7: 83-6.

[21] Ferry SA, Andersson SO, Burman LG, et al. Optimized urinary microscopy for assessment of bacteriuria in primary care. J Fam Pract 1990; 31: 153-61.

[22] Warren JW, Abrutyn E, Hebel JR, et al. Guidelines for antimicrobial treatment of uncomplicated acute bacterial cystitis and acute pyelonephritis in women. Infectious Diseases Society of America (IDSA). Clin Infect Dis 1999; 29: 745-58.

[23] Flottorp S, Oxman AD, Cooper JG, et al. Retningslinjer for diagnostikk og behandling av akutte vannlatingsplager hos kvinnor (In Norwegian). [Guidelines for diagnosis and treatment of acute urinary tract problems in women]. Tidsskr Nor Laegeforen 2000; 120: $1748-53$.

[24] Scottish Intercollegiate Guidelines Network SIG. Management of suspected bacterial urinary infection in adults. A national clinical guideline 2006. Available at: www.sign.ac.uk

[25] Nedre urinvagsinfektion (UVI) hos kvinnor - Behandlingsrekommendation. Information från Lakemedelsverket 2:2007 (In Swedish). [Lower urinary tract infections (UTI) in womenGudelines for antimicrobial treatment]. Solna, Sweden: Information from The Swedish Medical Products Company 2: 2007.

[26] Hummers-Pradier E, Ohse AM, Koch M, Heizmann WR, Kochen M. Management of urinary tract infections in female. J Fam Pract $2005 ; 22: 71-7$.

[27] Gupta K, Hooton TM, Stamm WE. Increasing antimicrobial resistance and management of uncomplicated community-acquired urinary tract infections. Ann Intern Med 2001; 135: 41-50.

[28] Kahlmeter G. An international survey of the antimicrobial susceptibility of pathogens from uncomplicated urinary tract infections: the ECO.SENS Project. J Antimicrob Chemother 2003; 51: 69- 76 .

[29] Zhanel GG, Hisanaga TL, Laing NM, et al. The NAUTICA Group, Hoban DJ. Antibiotic resistance in Esherichia coli outpatient urinary isolates: final results from the North American Urinary Tract Infection Collaborative Alliance (NAUTICA). Int J Antimicrob Agents 2005; 26: 380-8.

[30] Schito GC, Naber KG, Botto H, et al. The ARESC study: an international survey on the antimicrobial resistance of pathogens involved in uncomplicated urinary tract infections. Int J Antimicrob Agents 2009; 34: 407-13.

[31] Costelloe C, Metcalfe C, Lovering A, et al. Effect of antibiotic prescribing in primary care on antimicrobial resistance in individual patients: systematic review and meta-analysis. BMJ 2010 May 18; 340: c2096.

[32] Hillier S, Roberts Z, Dunstan F, et al. Prior antibiotics and risk of antibiotic- resistant community-acquired urinary tract infection: a case-control study. J Antimicrob Chemother 2007; 60: 92-9.

[33] Cars O, Hogberg LD, Murray M, et al. Meeting the challenge of antibiotic resistance. BMJ 2008 Sep 18; 337: a1438.

[34] Butler CC, Heginbothom M, Mason B, et al. Containing antibiotic resistance: decreased antibiotic-resistant coliform urinary tract infections with reduction in antibiotic prescribing by general practices. Br J Gen Pract 2007; 57: 785-92.

[35] Bossuyt PM, Reitsma JB, Bruns DE, et al. The STARD statement for reporting studies of diagnostic accuracy: explanation and elaboration. Clin Chem 2003; 49: 1-6.

[36] Bossuyt PM, Reitsma JB, Bruns DE, et al. The STARD group. towards complete and accurate reporting of studies of diagnostic accuracy: the stard initiative. Clin Chem 2003; 49: 7-18.

[37] Sternheimer R, Malbin . Clinical recognition of pyelonephritis, with a new stain for urinary sediments. Am J Med 1951; 11: 31223.

[38] Bylén I, Ekesrydh S, Ferry SA, et al. Vardprogram UVI primarvarden Vasterbotten. (In Swedish). [Guidelines for management of patients with urinary tract infections in primary health care in the county of Vasterbotten]. Umea, Sweden: Vasterbottens Lans Landsting; 1981.

[39] Ransohoff DF, Feinstein AR. Problems of spectrum and bias in evaluating the efficacy of diagnostic tests. N Engl J Med 1978; 299: 926-36. 
[40] Hobbs FDR, Delaney BC, Fitzmaurice DA, et al. A review of near patient testing in primary care. Health Technol Assess 1997; 1: 1229.

[41] Little P, Turner S, Rumsby K, et al. Dipsticks and diagnostic algorithms in urinary tract infection: development and validation, randomised trial, economic analysis, observational cohort and qualitative study. Health Technol Assess 2009 Mar 13 (19): iii-iv, ix-xi, 1-73.

[42] Aspevall O, Hallander H, eds. Referensmetodik for laboratoriediagnostik vid kliniskt bakteriologiska laboratorier. I. Infektionsdiagnostik. I 5. Urinvagsinfektioner/bakteriuri. Andra upplagan. Smittskyddsinstitutet 2000. (In Swedish). [Reference methodology for laboratory diagnostics at clinical bacteriological laboratories. I. Infectious diagnostics. I 5. Urinary tract infections/bacteriuria. Second edition]. Solna, Sweden: The Swedish Institute for Infectious Disease Control; 2000.

[43] Kouri T, Fogazzi G, Gant V, et al. eds. ECLM-EUROPEAN URINALYSIS GROUP. European Urinalysis Guidelines. Scand J Clin Lab Invest 2000; 60 (Suppl 231): 1-96.

[44] Rubin RH, Shapiro ED, Andriole VT, et al. Evaluation of new antiinfective drugs for the treatment of urinary tract infection. Infectious Diseases Society of America and the Food and Drug Administration. Clin Infect Dis 1992; 15: 216-27.

[45] Gupta K, Hooton TM, Naber KG, et al. International clinical practice guidelines for the treatment of acute uncomplicated cystitis and pyelonephritis: A 2010 update by the infectios diseases society of America and the European society for microbiology and infectious diseases. Clin Inf Dis 2011; 52: 103-20.

[46] Immergut MA, Govan GE, Palmer JM. The myth of the clean catch urine specimen. Urology 1981; 17: 339-40.

[47] Baerheim A, Laerum E. Home-voided urine specimens in women. Diagnostic agreement with clean- catch midtream specimens. Scand J Prim Health Care 1990; 8: 207-11.
[48] Bradbury SM. Collection of urine specimen in general practice: to clean or not to clean. J R Coll Gen Pract 1988; 33: 363-5.

[49] Baerheim A, Digranes A, Hunskaar S. Evaluation of urine sampling technique: bacterial contamination of samples from women students. Br J Gen Pract 1992; 42: 241-3.

[50] Leisure MK, Dudley SM, Donowitz LG. Does a clean-catch urine sample reduce bacterial contamination? N Engl J Med 1993; 328: 289-90.

[51] Lifshitz E, Kramer L. Outpatient urine culture. Does collection technique matter? Arch Intern Med 2000; 160: 219-21.

[52] Jellheden B, Norrby RS, Sandberg T. Symptomatic urinary tract infection in women in primary health care. Bacteriological, clinical and diagnostic aspects in relation to host response to infection. Scand J Prim Health Care 1996; 14: 122-8.

[53] Little P, Turner S, Rumsby K, et al. Validating the prediction of lower urinary tract infection in primary care: sensitivity and specificity of urinary dipsticks and clinical scores in women. Br J Gen Pract 2010; 60: 495-500.

[54] McIsaac WJ, Low DE, Biringer A, et al. The impact of empirical management of acute cystitis on unneccesary antibiotic use. Arch Intern Med 2002; 162: 600-5.

[55] McIsaac WJ, Moineddin R, Ross S. Validation of a decision aid to assist physicians in reducing unnecessary antibiotic drug use for acute cystitsis. Arch Intern Med 2007; 167: 2201-6

[56] Vellinga A, Cormican M, Hanahoe B, et al. Antimicrobial management and appropriateness of treatment of urinary react infection in general practice in Ireland. BMC Fam Pract 2011 Oct 3; $12: 108$.

[57] Delanghe Joris, Speeckaert Marijn. Preanalytical requirements of urinalysis. Biochemica Medica 2014; 24: 89-104.

Received: March 16, 2015

Revised: May 07, 2015

Accepted: June 16, 2015

(C) Ferry et al:; Licensee Bentham Open.

This is an open access article licensed under the terms of the (https://creativecommons.org/licenses/by/4.0/legalcode), which permits unrestricted, noncommercial use, distribution and reproduction in any medium, provided the work is properly cited. 